\title{
Measurement and Interpretation of Time Variations of Particulate Matter Observed in the Busan Coastal Area in Korea
}

\author{
Cheol-Hee Kim* and Hye-Young Son \\ Department of Atmospheric Sciences, Pusan National University, San 30, Jangjeon-Dong, Geumjeong-Gu, Busan 609-735, Korea \\ *Corresponding author. Tel: +82-51-510-3687, E-mail: chkim2@pusan.ac.kr
}

\begin{abstract}
In order to investigate the effects of local and synoptic meteorological conditions on urban scale particulate air pollutants observed over the Busan coastal area, power spectrum analysis was applied to observed particulate matter with an aerodynamic diameter $\leq 10 \mu \mathrm{m}\left(\mathrm{PM}_{10}\right)$ for the period from 1 October, 1993 to 31 December, 2004. Fast Fourier Transform (FFT) analysis was used to obtain the hourly mean observed $\mathrm{PM}_{10}$ concentrations to identify different periodicity scales of $\mathrm{PM}_{10}$ concentrations. The results showed that, aside from the typical and well-known periodicities such as diurnal and annual variations caused by anthropogenic influences, three other significant power spectral density peaks were identified: 7-day, 21-day and 2.25-year periodicities. Cospectrum analysis indicated that the seven-day variations were closely related to the synoptic meteorological conditions such as weak wind speed, which are relevant to the stagnant high pressure system slowly passing through the Korean Peninsula. The intra-seasonal 21-day variation was negatively correlated with wind speed but was consistently positively correlated with relative humidity, which is related to aerosol formation that can be achieved as a result of the hygroscopic characteristics of aerosols. However, the quasibiennial 2.25-year variation was correlated with the frequency of Asian dust occurrence, the periodicities of which have been recorded inter-annually over the Korean Peninsula.
\end{abstract}

Key words: $\mathrm{PM}_{10}$ concentrations, Meteorological parameters, Fast Fourier Transform (FFT) analysis, Asian dust

\section{INTRODUCTION}

Particulate matter has recently been recognized to influence climate forcing to offset warming caused by greenhouse gases such as carbon dioxide (Rosenfeld et al., 2008; Kiehl and Briegle, 1993), and many global studies of direct forcing by diverse aerosol types have been carried out. Particulate matter is a major pollutant causing visibility reduction in many cities. Particulate matter with an aerodynamic diameter $\leq 10 \mu \mathrm{m}$, called $\mathrm{PM}_{10}$, is a potential carrier of its compounds into human and animal respiratory systems causing respiratory diseases (Gurjar et al., 2010; Shima and Yoda, 2009; Harrison et al., 1997).

So far, some studies of meteorological influences associated with urban $\mathrm{PM}_{10}$ concentrations have been conducted based on observed $\mathrm{PM}_{10}$ concentrations in many cities (Tai et al., 2010; Janssen et al., 1997). However, most documented urban scale air pollutants including $\mathrm{PM}_{10}$ concentration analysis in association with meteorological variables have used simple statistical methods such as means and variance analysis (Kim et al., 2007; Milionis and Davies, 1994; Lewis and Einfeld, 1985; Shah et al., 1985).

Spectral analysis has been used as a standard method in meteorology to detect periodicities of meteorological variables (Rotach, 1995). Recently, some previous air pollution studies used spectral analysis to explain the influence of different air pollution sources (Tchepel et al., 2010; Hies et al., 2000; Sebald et al., 2000). Previous researchers reported that the urban-scale $\mathrm{PM}_{10}$ time series are mainly determined by two factors: the emission process (due to the influence of anthropogenic processes) and the dilution process (due to the influence of turbulent meteorological processes) (Hies et al., 2000). However, as both the emission process and dilution process have cyclic patterns, spectral analysis is one of the most promising ways to detect concentration peaks and analyze the observed urban scale $\mathrm{PM}_{10}$ concentrations.

In the Busan metropolitan area (BMA) in Korea, a large database of hourly $\mathrm{PM}_{10}$ concentrations measured at several sites in the urban area since early 1990 are available. However, the characteristic features of time variation of observed $\mathrm{PM}_{10}$ concentrations have not 
been fully explored yet. The purpose of this study was to characterize variation in the BMA by examining periodicities of the measured $\mathrm{PM}_{10}$ concentrations for the period from 1 October, 1993 to 31 December, 2004 using the power spectrum analysis.

\section{MATERIALS AND METHODS}

\subsection{Study Area}

Busan, the second largest city in Korea, is located in the southeastern tip of the Korean Peninsula (Fig. 1) and has an area of $760 \mathrm{~km}^{2}$ and a population of approximately four million. Busan has a complex terrain including an irregular coastline and moderately high (i.e., $<1 \mathrm{~km}$ above sea level) mountains. Fig. 1 shows the locations of the BMA and $\mathrm{PM}_{10}$ monitoring sites. The BMA has rapidly urbanized and industrialized such that the city has experienced a substantial increase in urban scale air pollutants including $\mathrm{PM}_{10}$. Note that the urban center (BC in Fig. 1) is situated approximately $4 \mathrm{~km}$ away from the coastline in a valley, which is covered with tall buildings and roads. Prevailing synoptic winds over the BMA are generally northwesterlies in winter and southwesterlies in summer. During the warm season (i.e., from April to September), a stagnant or slowly moving high pressure system with weak surface wind speed frequently occurs. These meteorological conditions could affect the high $\mathrm{PM}_{10}$ concentration levels observed in this region.

The BMA has various pollutant emission sources such as vehicles, industrial facilities, ships and urban activity. The highest emissions occur over the downtown area, located about $4 \mathrm{~km}$ from the coastline, as well as over the industrialized area in the southwestern part of the BMA. Annual total $\mathrm{PM}_{10}$ emissions in the BMA from point, line and area sources have been reported in the MOE (Ministry of Environment, 2003). There are approximately 862,000 registered vehicles in the BMA and the heavy traffic contributes a large part of these emissions.

\section{2 Data}

Hourly $\mathrm{PM}_{10}$ concentration data were obtained from nine monitoring sites (Fig. 1) operated by MOE for the period from 1993 to 2004 . $\mathrm{PM}_{10}$ concentrations in the BMA were measured at traffic stations, and in residential and industrial areas. During the same period, meteorological variables obtained at the Korean meteorological observation station located in the BMA (Fig. 1) were used. Meteorological variables including hourly measurements of wind speed, temperature, and surface pressure were selected as input data for the cross-spectral analysis to examine the correlation between $\mathrm{PM}_{10}$ concentrations and meteorological variables.

\section{3 Methods}

$\mathrm{PM}_{10}$ time series were converted to spectral power densities over the frequency domain using the FFT algorithm. The power density spectrum (PDS) produced from the FFT analysis allowed the detection of periodic components in the $\mathrm{PM}_{10}$ time series by splitting up the variance to the underlying periodicities. We analyzed the cyclic measurement behaviors to explore the characteristics of time variation. Further, the cospectra and phase spectra between $\mathrm{PM}_{10}$ and the meteorological data including temperature, wind speed, and surface pressure observed in the BMA were computed to determine their association with each periodicity.

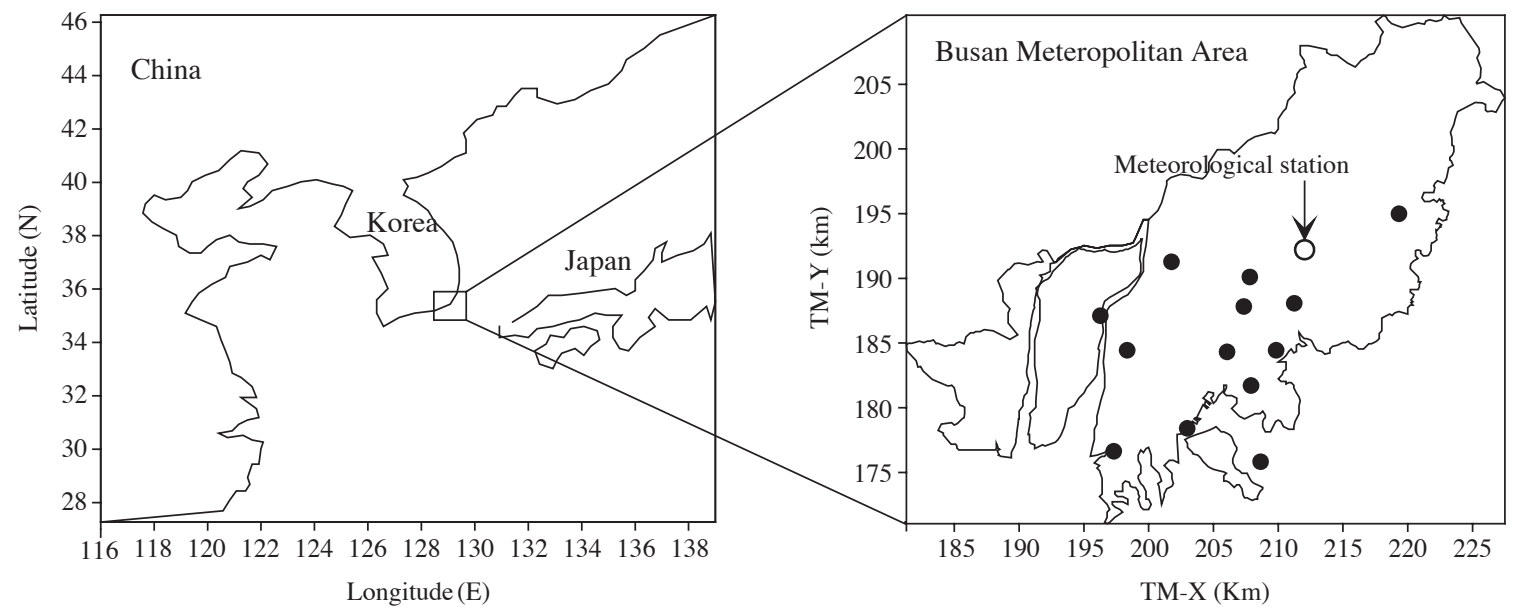

Fig. 1. Busan metropolitan area in southeastern Korea with the locations of $\mathrm{PM}_{10}$ concentration monitoring sites. 


\section{3. 1 Fast Fourier Transform (FFT)}

FFT is a simple algorithm used to perform a series of computations to determine the discrete Fourier transform much more rapidly than other available algorithms because it has been factored and restructured to take advantage of the rapid binary computation processes of the digital computer. FFT is restricted to data sets with $\mathrm{N}=2^{\mathrm{m}}$, where $\mathrm{m}$ is any integer. FFT has been used widely as a standard method in meteorology (Hies et al., 2000), analysis of turbulence (Sebald et $a l ., 2000$ ) and air pollution studies (Rotach, 1995).

\subsection{Detrending, KZ Filter, and Cospectrum}

Observed $\mathrm{PM}_{10}$ concentrations and meteorological variables were transformed logarithmically and linear trends were removed prior to all further analysis to eliminate red noise. Even after the detrending process, sharp edges of the data window caused what is known as leakage (end effect), where spectral estimates from any one frequency are contaminated with some spectral amplitude leaking in from neighboring frequencies (Stull, 1988). A variety of smoother edges have been used to reduce the leakage, and in this study, we used the Kolmogorov-Zurbenko (KZ) filter (Lee et al., 2008; Eskridge et al., 1997; Rao and Zurbenko, 1994). The $\mathrm{KZ}$ filter is a low-pass filter implemented via iteration of a simple moving average. The length of the simple moving average, $\mathrm{m}$, and the number of iterations, $\mathrm{k}$, determine the shape of the energy transfer function. The $\mathrm{KZ}(\mathrm{m}, \mathrm{k})$ filter is defined as $\mathrm{k}$ applications of a simple moving average of $\mathrm{m}$ points. The moving average can be expressed as

$$
\mathrm{Y}_{\mathrm{t}}=\frac{1}{\mathrm{~m}_{\mathrm{S}}} \sum_{-(\mathrm{m}-1) / 2}^{(\mathrm{m}-1) / 2} \mathrm{X}(\mathrm{t}+\mathrm{s})
$$

where $X$ is the original time series and $t$ is time. The series $Y_{t}$ becomes the input for the second pass, and so on. By taking the difference between two KZ filters with different parameters, $\mathrm{m}$ and $\mathrm{k}$ (and thus different transmission characteristics), a band-pass filter is created. The time series produced by $\mathrm{k}$ iterations of the filter described by this equation is denoted $Y_{t}^{k}$. The purpose of the filtering is to remove all fluctuations from the original data within the intended time period. In this study, we applied $m=3$ and $k=3$ to the time series of $\mathrm{PM}_{10}$ concentrations. This filtered out fluctuations with a period less than 12 hours and maintained all other fluctuations without as described in Tchepel et al. (2010). Additional details on the KZ filter can be found in Hogrefe et al. (2000), Rao and Zurbenko (1994), and Porter et al. (2001).

Like the spectrum analysis for a single variable, cross spectrum analysis relates the spectra of two variables. When we define $G_{A}=\left|F_{A}(n)\right|^{2}$, and $G_{B}=\left|F_{B}(n)\right|^{2}$ as the spectral energy of frequency, $\mathrm{n}$, for variables, A and $\mathrm{B}$, we can rewrite it as $\mathrm{G}_{\mathrm{A}}=\mathrm{F}_{\mathrm{A}} * \cdot \mathrm{F}_{\mathrm{A}}$, and $\mathrm{G}_{\mathrm{A}}=$ $\mathrm{F}_{\mathrm{B}} * \cdot \mathrm{F}_{\mathrm{B}}$, for variables $\mathrm{A}$ and $\mathrm{B}$ respectively, where $\mathrm{F}_{\mathrm{A}} *$ and $\mathrm{F}_{\mathrm{B}} *$ are the complex conjugates of $\mathrm{F}_{\mathrm{A}}$ and $\mathrm{F}_{\mathrm{B}}$, respectively. Let $\mathrm{F}_{\mathrm{A}}=\mathrm{F}_{\mathrm{Ar}}+\mathrm{iF}_{\mathrm{Ai}}$, and $\mathrm{F}_{\mathrm{B}}=\mathrm{F}_{\mathrm{Br}}+\mathrm{iF}_{\mathrm{Bi}}$, where $r$ and $i$ denote real and imaginary parts, respectively. The cross spectrum between variable A and B is then defined as

$$
\mathrm{G}_{\mathrm{AB}}=\mathrm{F}_{\mathrm{A}} * \cdot \mathrm{F}_{\mathrm{B}}=\mathrm{Co}-\mathrm{i} \cdot \mathrm{Q},
$$

where $\mathrm{Co}\left(=\mathrm{F}_{\mathrm{Ar}} \cdot \mathrm{F}_{\mathrm{Br}}+\mathrm{F}_{\mathrm{Ai}} \cdot \mathrm{F}_{\mathrm{Bi}}\right)$ is called the cospectrum, and $\mathrm{Q}\left(=\mathrm{F}_{\mathrm{Ai}} \cdot \mathrm{F}_{\mathrm{Br}}-\mathrm{F}_{\mathrm{Ar}} \cdot \mathrm{F}_{\mathrm{Bi}}\right)$, the quadrature spectrum. The cospectrum is frequently used in micrometeorology because the sum over frequency of all cospectral amplitudes, Co, equals the covariance between A and B (Stull, 1988).

\section{RESULTS AND DISCUSSION}

\section{1 Overall Characteristics of the Spectral Power Density of $\mathbf{P M}_{10}$}

The monthly variations in $\mathrm{PM}_{10}$ concentrations were averaged for all 13 monitoring sites in the BMA for the recent four years (Fig. 2). PM $_{10}$ concentrations were relatively high in the spring season and lower during the summer compared to other seasons. The low concentrations in summer are partly attributed to the wash-out effect due to large amounts of precipitation during the rainy season. Nevertheless, an intermittent cloudless day might also generate a secondary aerosol due to strong solar radiation. Dominant precipitation effects during the summer were also found in other cities in Korea (Ko et al., 2010; Lim et al., 2010; Lee et al., 2002). In 2002, several severe Asian dusts were observed in Korea in both March and April, and thus the hourly mean $\mathrm{PM}_{10}$ concentration exceeded $1,000 \mu \mathrm{g} / \mathrm{m}^{3}$ in several cities, resulting in high $\mathrm{PM}_{10}$ concentrations for the year of 2002. Except for the recent spring seasons, $\mathrm{PM}_{10}$ concentrations were detected near $80 \mu \mathrm{g} / \mathrm{m}^{3}$.

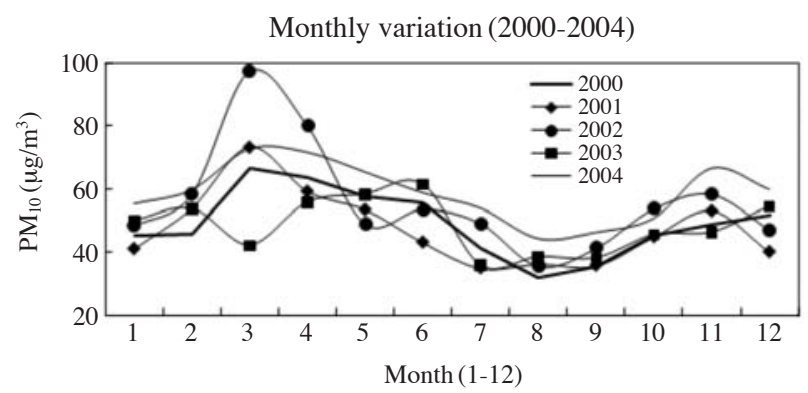

Fig. 2. Annual variations of observed $\mathrm{PM}_{10}$ concentrations for recent years in Busan. 
(a)

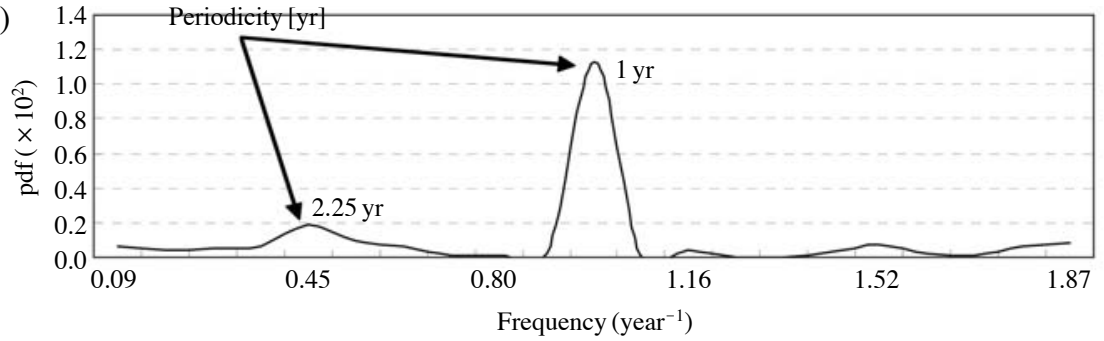

(b)

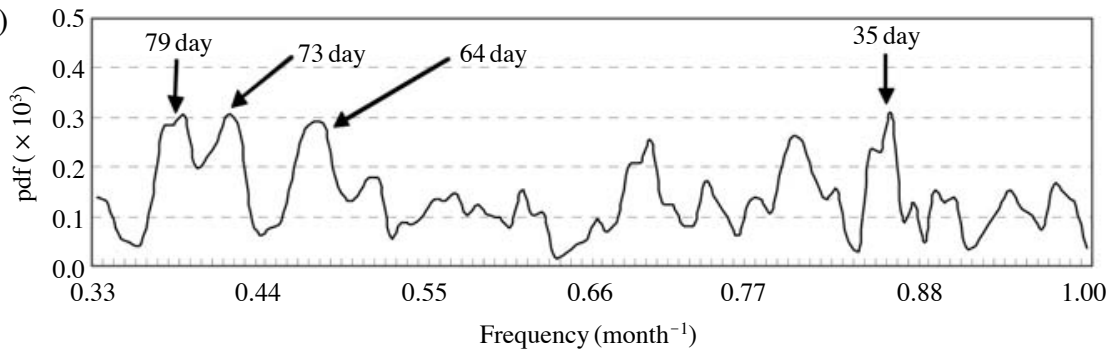

(c)

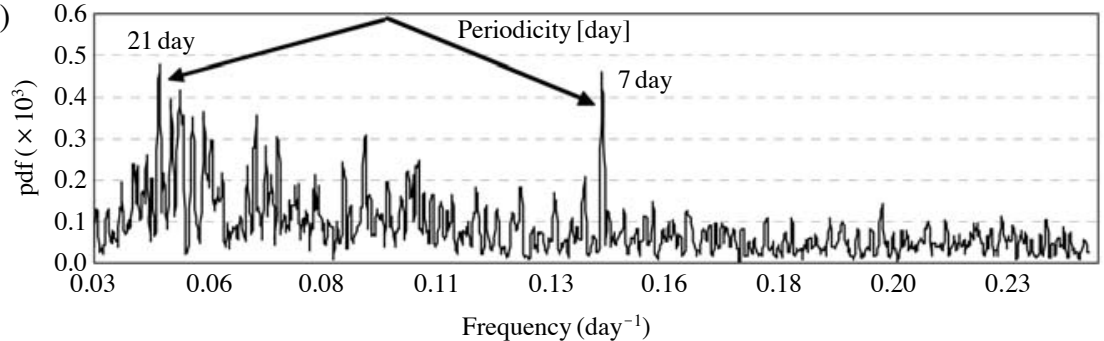

(d)

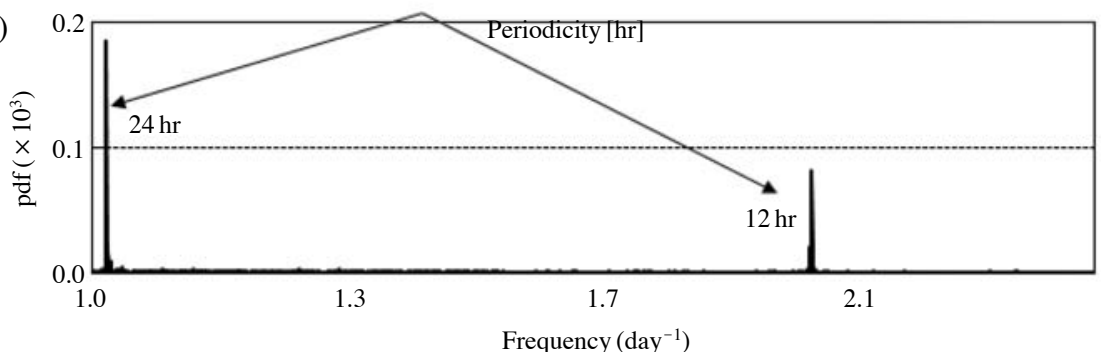

Fig. 3. Power density spectra of $\mathrm{PM}_{10}$ time series. The frequency dimension is time ${ }^{-1}\left(\mathrm{year}^{-1}\right.$ month $^{-1}$ or day $^{-1}$ ) and the dimension of periodicity is time (year or day).

Fig. 3 shows the distribution of spectral power density of $\mathrm{PM}_{10}$ concentrations. Fig. 3(a) illustrates the distribution of PDS for the low frequency (a period of more than one year), and shows two significant peaks: 2.25 years (corresponding to a frequency of $1.2 \times 10^{-3}$ day $^{-1}$ ) and 1 year. However, in the period from one month to one year as in Fig. 3(b), the PDSs at 73-79 days, 64 days, and 35 days were relatively higher, although the peak signals were rather insignificant compared with the lower frequency (Fig. 3(a)). For the relatively high frequency illustrated in Fig. 3(c), two more significant PDSs were detected at periods of 21 days and 7 days. The highest frequencies with a period less than 24 hours indicated in Fig. 3(d) showed no significance trends except for strong diurnal and 12-hour periodicities.

Hies et al. (2000) presented different air pollution sources in an elementary carbon time series in Berlin, Germany, and identified typical periodicities caused by anthropogenic influences using coherence and phase spectra. They concluded that domestic heating by coal combustion has a period of 365 days, and traffic volume contributed to the 7-day peak in their spectrum (Hies et al., 2000). They confirmed the source of 365-day peak by creating a new time series without the cycles of weekly traffic flow and the heating period, and 
(a)

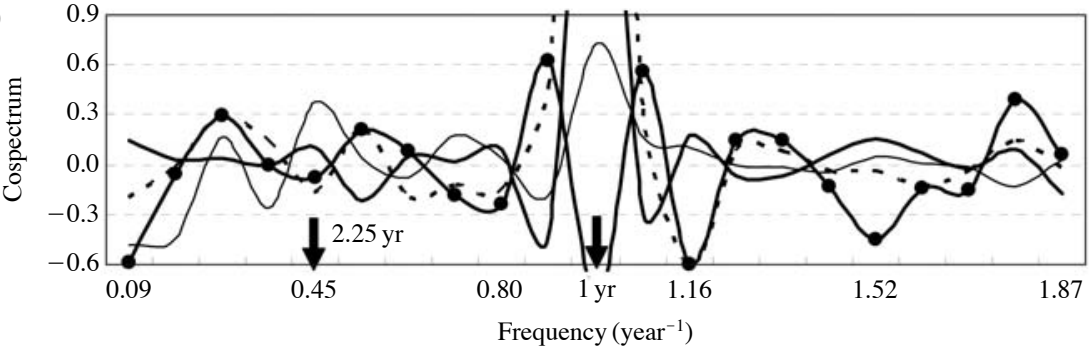

(b)

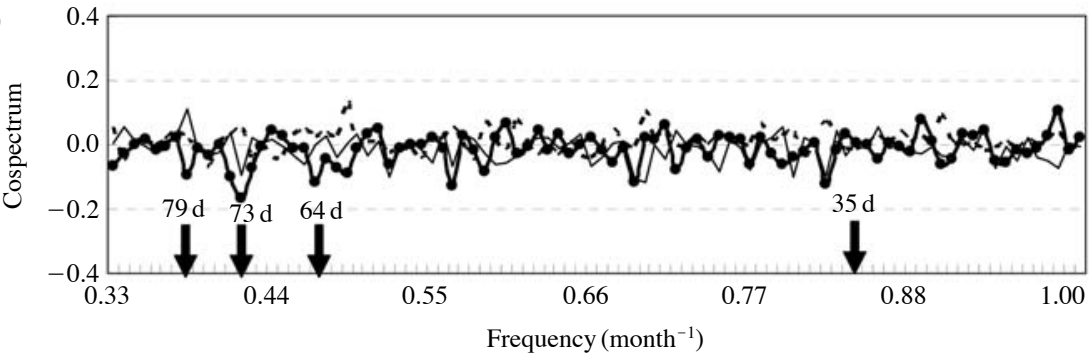

(c)

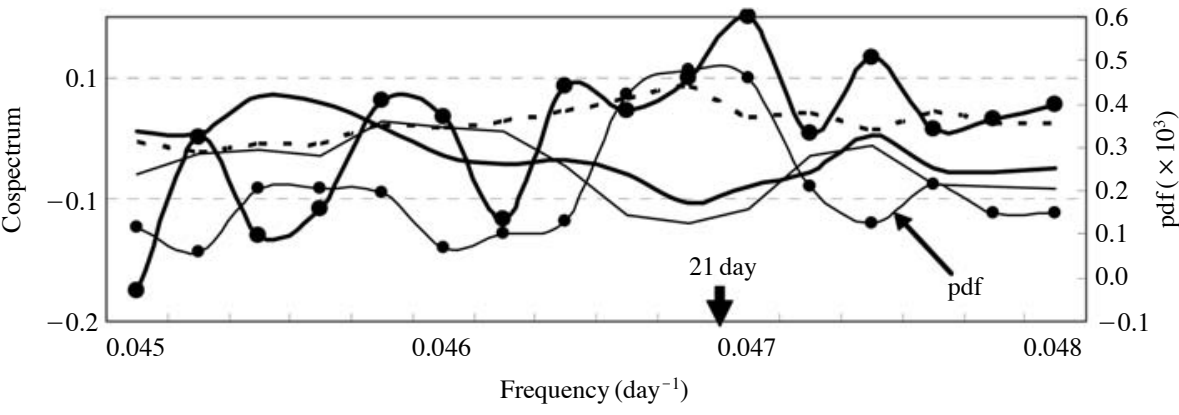

(d)

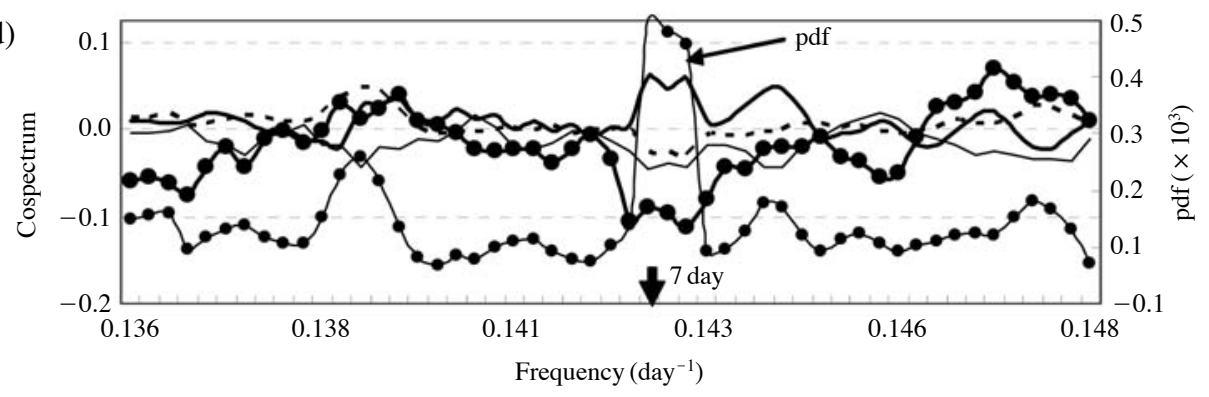

- Temp. - Wind speed

Pressure

Relative humidity

Fig. 4. Cospectrum between $\mathrm{PM}_{10}$ time series and meteorological parameters (wind speed, temperature, and surface pressure in the Busan metropolitan area).

they also confirmed the correlation of the 7-day peak of air pollutant with anthropogenic influences using statistics from a traffic station where the weekly periodicity of the traffic influence was of great importance (Hies et al., 2000). In this study, we also calculated the cospectrum using four time series of observed wind speed, temperature, surface pressure, and relative humidity, and tried to interpret in more detail the cor- relation between the periodicity of $\mathrm{PM}_{10}$ concentrations and meteorological variables in order to examine the time variations of $\mathrm{PM}_{10}$ concentrations observed in the Busan coastal area in Korea.

\section{2 Inter-annual Power Densities of the Cospectrum}

Fig. 4 shows the PDS of the cospectrum between 
$\mathrm{PM}_{10}$ and each meteorological variable. All four meteorological variables were well correlated with $\mathrm{PM}_{10}$ concentrations at the 365-day period: positive correlations with temperature, wind speed and surface pressure, and negative correlations with relative humidity (Fig. 4(a)). These correlations support the role of meteorological annual variations in the annual time series of $\mathrm{PM}_{10}$ concentrations along with anthropogenic emissions described by Hies et al. (2000). The meteorological influence could be a factor affecting pollutant transport into or out of the BMA, although anthropogenic emissions from domestic heating and other sources are still the major factors.

In contrast, the cospectrum at the period of $2.25 \mathrm{yrs}$ had a positive correlation with wind speed with small phase shifts, a slight negative correlation with temperature (phase shift of $120^{\circ}$ out of phase), and little correlation with surface pressure, indicating no significant correlations with local meteorological variables in the underlying $\mathrm{PM}_{10}$ concentration variation. Therefore, this quasi-biennial oscillation requires further study with longer records of $\mathrm{PM}_{10}$ measurement data (usually the length of the record should be ten times as long as the longest significant period (Wolff et al., 1985)). The $2.25 \mathrm{yr}$ periodicity is of particular interest because the observed number of Asian dust occurrences shows a close periodicity of $2.25 \mathrm{yr}$ (Fig. 5), implying the importance of quasi-biennial frequencies of transboundary processes of observed particulate matter that partially originates from Asian dusts.

\section{3 Intra-seasonal/Intra-monthly Power Densities of Cospectrum}

Figs. 4(b)-(d) show variations in seasonal or intraseasonal frequencies that were higher than inter-annual frequencies with less than a one-year period. No appreciable correlations with meteorological variables for intra-seasonal variations were found (Fig. 4(b)). For example, the calculated cospectrum of $\mathrm{PM}_{10}$ with wind speed was positive at a period of 79 days but negative at a period of 73 days, implying no significant periodical correlation with meteorological variables.

However, for relatively higher frequencies (Fig. 4(c) and 4(d)), significant values in the cospectra occurred between $\mathrm{PM}_{10}$ and wind speed at periods of 21 days and 7 days. Looking at the period of 21 days in Fig. 4(c), we can clearly see that the observed $\mathrm{PM}_{10}$ concentration was negatively correlated with wind speed, but consistently correlated positively with relative humidity. This relation might be due to the hygroscopic characteristics of aerosols leading to secondary aerosol formation under weak wind speed through condensation, coagulation, hygroscopic growth and heterogeneous chemistry.

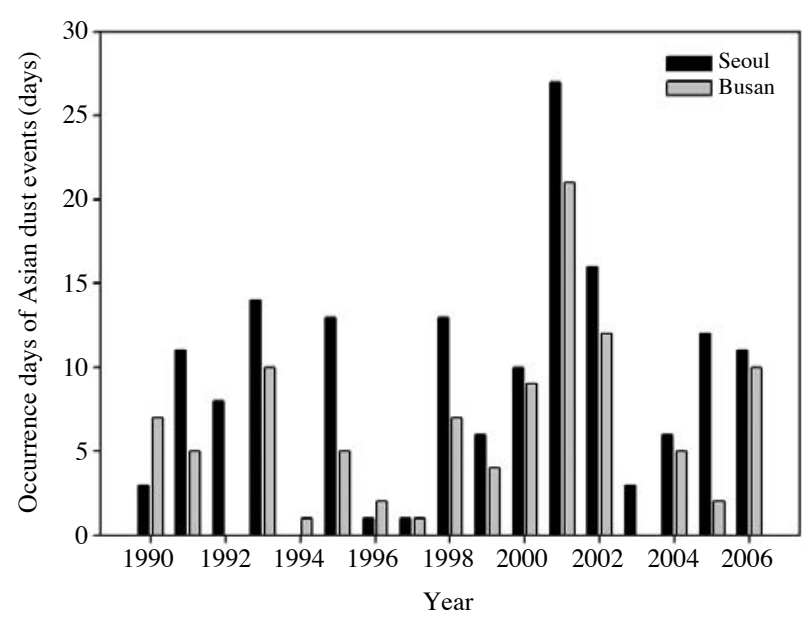

Fig. 5. Annual variations in the occurrence of Asian dust events observed in Seoul and the Busan metropolitan area.

Conversely, the seven-day period (Fig. 4(d)), had a negative correlation with wind speed and a positive correlation with pressure. These relationships indicate that $\mathrm{PM}_{10}$ concentrations tend to be high when wind speed is weak and pressure is high, implying that the stagnant high pressure of synoptic conditions resulting in high $\mathrm{PM}_{10}$ concentrations caused by weak ventilation was due to weak wind speed. The phase angle between $\mathrm{PM}_{10}$ concentrations and wind speed was approximately $186^{\circ}$ out of phase. This implies stronger dilution of $\mathrm{PM}_{10}$ concentrations by higher wind velocities inside the BMA and vice versa.

The highest frequencies with a period less than 24 hours showed no significant trends except for strong diurnal and 12-hour periodicities (Fig. 4(d)), which were mostly associated with diurnal emission variation together with meteorological phenomena such as onand/or off-shore wind fields derived by local land-sea breeze circulations over the Busan coastal area.

\section{CONCLUSIONS}

Fast Fourier Transform (FFT) analysis was applied to $\mathrm{PM}_{10}$ concentrations observed in the Busan Metropolitan area for the period from 1 October, 1993 to 31 December, 2004. First, we split up the variance of a time series to its base periodicities using the FFT algorithm. We then applied cross spectral analysis to the correlation in the frequency (or spectral) domain between two different time series at a certain frequency range to examine the relationship between periodicities and meteorological variables including wind speed, temperature and surface pressure.

The results revealed several significant peaks in the 
density of power spectrum at periods of $2.25 \mathrm{yrs}, 365$ days, 73-79 days, 65 days, 34 days, 21 days, and 7 days. Among them, 2.25 yrs, 21 days and 7 days had higher correlations with meteorological variables. The cospectrum analysis showed that the period of 21 days was closely related to weak wind speed and high relative humidity, implying the role of hygroscopic growth of secondary aerosols including condensation and coagulation processes. The seven-day period was related to weak wind speed, indicating that low $\mathrm{PM}_{10}$ concentrations were attributed to dilution influenced by wind velocity, and high $\mathrm{PM}_{10}$ concentrations were related to the stagnant or slow-moving high pressure synoptic system passing through the Korean peninsula.

However, the 2.25-yr oscillation was not clearly correlated with urban meteorological quantities in the BMA. However it appeared to be associated with the frequency of Asian dust occurrence, the periodicities of which are also observed as inter-annual frequencies over the Korean Peninsula. However, this quasi-biennial oscillation of the observed $\mathrm{PM}_{10}$ could not be completed due to a lack of data; long-term monitoring data and other information related to the surface conditions over the Asian dust source regions are required.

\section{ACKNOWLEDGEMENTS}

This work was supported by the Korea Research Foundation Grant funded by the Korean Government (KRF-2008-331-C00285).

\section{REFERENCES}

Eskridge, R.E., Ku, J.Y., Rao, S.T., Porter, P.S., Zurbenko, I.G. (1997) Separating different scales of motion in time series of meteorological variables. Bulletin of the American Meteorological Society 78, 1473-1483.

Gurjar, B.R., Jain, A., Sharma, A., Agarwal, A., Gupta, P., Nagpure, A.S., Lelieveld, J. (2010) Human health risks in megacities due to air pollution. Atmospheric Environment 44(36), 4606-4613.

Harrison, R., Deacon, A., Jones, M. (1997) Source and processes of $\mathrm{PM}_{10}$ and $\mathrm{PM}_{2.5}$ particulate matter in Birmingham 1997. Atmospheric Environment 31, 4103-4117.

Hies, T., Treffeisen, R., Sebald, L., Reimer, E. (2000) Spectral analysis of air pollutants. Part 1: elemental carbon time series. Atmospheric Environment 34, 3495-3502.

Hogrefe, C., Rao, S.T., Zurbenko, I.G., Porter, P.S. (2000) Interpreting information in time series of ozone observations and model predictions relevant to regulatory policies in the eastern United States. Bulletin of the American Meteorological Society 81, 2083-2106.

Janssen, N., Van Manson, D., Van der Jagt, K., Hoek, G.
(1997) Mass concentration and elemental composition of airborne particulate matter at street and background locations. Atmospheric Environment 31, 1185-1193.

Kiehl, J.T., Briegle, B.P. (1993) The relative roles of sulfate aerosols and greenhouse gases in climate forcing. Science 260, 311-314.

Kim, J.-A., Jin, H.-A., Kim, C.-H. (2007) Characteristics of time variations of $\mathrm{PM}_{10}$ concentrations in Busan and interpreting its generation mechanism using meteorological variables (in Korean). Journal of the Environmental Sciences 16(10), 1157-1167.

Ko, H.-J., Kang, C.-H., Kim, W.-H., Lee, S.-B., Kang, H.-S. (2010) Long-term variation of ionic constituent concentrations in TSP at Jeju Island (in Korean). Journal of Korean Society for Atmospheric Environment 26(4), 420-431.

Lee, J.-Y., Kong, B.-J., Han, J.-S., Lee, M.-D. (2008) Long term analysis of $\mathrm{PM}_{10}$ concentration in Seoul using $\mathrm{KZ}$ filter (in Korean). Journal of Korean Society for Atmospheric Environment 24(1), 63-71.

Lee, S.-B., Bae, G.-N., Kim, Y.-P., Jin, H.-C., Yoon, Y.-S., Moon, K.-C. (2002) Aerosol characteristics at Tokchok island in the Yellow Sea (in Korean). Journal of Korean Society for Atmospheric Environment 18(4), 305-316.

Lewis, C., Einfeld, W. (1985) Origins of carbonaceous aerosols in Denver and Abbuquerque during winter. Environmental International 11, 243-247.

Lim, S., Lee, M., Kang, K.-S. (2010) Seasonal variations of $\mathrm{OC}$ and $\mathrm{EC}$ in $\mathrm{PM}_{10}, \mathrm{PM}_{2.5}$ and $\mathrm{PM}_{1.0}$ at Gosan superstation on Jeju Island (in Korean). Journal of Korean Society for Atmospheric Environment 26(5), 567-580.

Milionis, A.E., Davies, T.D. (1994) Regression on stochastic models for air pollution II: applications of stochastic models to examine the links between ground-level smoke concentrations and temperature inversions. Atmospheric Environment 28(17), 2811-2822.

MOE (Ministry of Environment Republic of Korea) (2003) Environmental statistics yearbook air quality emission. p. 107.

Porter, P.S., Rao, S.T., Zurbenko, I.G., Dunker, A.M., Wolff, G.T. (2001) Ozone air quality over North America: Part II. An analysis of trend detection and attribution techniques. Journal of Air \& Waste Management Association 51, 283-306.

Rao, S.T., Zurbenko, I.G. (1994) Detecting and tracking changes in ozone air quality. Journal of Air \& Waste Management Association 44, 1089-1092.

Rosenfeld, D., Lohmann, U., Raga, G.B., O'Dowd, C.D., Kulmala, M., Fuzzi, S., Reissell, A., Andreae, M.O. (2008) Flood or drought: How do aerosols affect precipitation? Science 321, 1309-1313.

Rotach, M.W. (1995) Profiles of turbulence statistics and above an urban street canyon. Atmospheric Environment 29, 1473-1486.

Sebald, L., Treffeisen, R., Reimer, E., Hies, T. (2000) Spectral analysis of air pollutants. Part 2: ozone time series. Atmospheric Environment 34, 3503-3509.

Shah, S., Kneip, T., Daisey, J. (1985) Source apportionment 
of carbonaceous aerosol in New York City by multiple linear regression. Journal of Air Pollution Control Association 35, 541-544.

Shima, M., Yoda, Y. (2009) An ecological study of lung cancer mortality and severe air pollution in the $1960 \mathrm{~s}$ in an industrial city in Japan. Asian Journal of Atmospheric Environment 3(1), 9-18.

Stull, R.B. (1988) An Introduction to Boundary Layer Meteorology. Kluwer Academic publications, pp. 295345.

Tai, A.P.K., Mickley, L.J., Jacob, D.J. (2010) Correlations between fine particulate matter $\left(\mathrm{PM}_{2.5}\right)$ and meteorological variables in the United States: Implications for the sensitivity of $\mathrm{PM}_{2.5}$ to climate change. Atmospheric
Environment 44(32), 3976-3984.

Tchepel, O., Costa, A.M., Martins, H., Ferreira, J., Monteiro, A., Miranda, A.I., Borrego, C. (2010) Determination of background concentrations for air quality models using spectral analysis and filtering of monitoring data. Atmospheric Environment 44(1), 106-114.

Wolff, P., Korsog, P., Stroup, D., Ruthkorky, M., Morrissey, M. (1985) The influences of local and regional sources on the concentrations of inhalable particulate matter in South-eastern Michigan. Atmospheric Environment 19, 305-313.

(Received 28 September 2010, accepted 3 May 2011) 